DOI: 10.1515/auseur-2016-0006

\title{
Linguistic Justice and Endangered Languages
}

\author{
Reinier SALVERDA \\ Fryske Akademy, Leeuwarden, the Netherlands, University College London \\ rsalverda@fryske-akademy.nl
}

\begin{abstract}
This contribution will engage with Van Parijs's approach to linguistic justice and his working principles for the reduction of unfairness in the language domain (in particular, the need for intervention and his territorial principle), reflecting on a range of cases of multilingual practice and linguistic coexistence - respectively, in the multilingual capital of the world which is London today; in Fryslân, the minority language area in northern Netherlands; and in Europe, through its European Charter of Regional Minority Languages.

Overall, my argument, on a theoretical level, is for the further exploration of the relationship between linguistic diversity and human rights in civil society; and, on a practical level, for the development of a World Language Atlas as envisaged by UNESCO, containing vital information on all the world's languages - an urgently needed basic resource for policy-making, to ensure, especially for the world's many endangered languages, the linguistic justice and fairness advocated by Van Parijs.
\end{abstract}

Keywords: European Charter of Regional Minority Languages, Frisian, linguistic coexistence, London multilingualism, territorial principle

\section{Introduction}

In this contribution, we will consider the ideas put forward by Philippe Van Parijs in his Linguistic Justice (2011), with particular reference to the endangered languages of Europe. In the first section below, we will discuss the issue of intervention in the domain of languages and explore how our thinking about linguistic justice may benefit from the multilingual practices we encounter today in metropolitan London and its civil society. In Section 2, we will argue for a modification of Van Parijs's territorial principle, so as to take account of the language-political lessons we can draw from the case of Frisian, a European minority language spoken by some 300,000 people in Fryslân, in the north of the Netherlands. In the final section, we will consider the instruments available to minority languages in the 
European Charter of Regional Minority Languages and discuss what such policy instruments can contribute to the well-being of those languages.

Our exploration of these three cases takes place in the context of relevant ideas on multilingualism and minority languages, put forward by organizations such as the WWF (World Wild Life Fund), the FEL (Foundation for Endangered Languages), and UNESCO. Our aim here is to see how these various sources of ideas, practices, and principles for a just, fair, and equal treatment of languages in the multilingual world we are living in can be combined with and contribute to the linguistic justice approach of Van Parijs.

\section{The Need for Interventions and the Multilingual Practices Developing in London}

My first point concerns Van Parijs's claim - arrived at through a series of politicaleconomic cost-benefit analyses of language learning situations - viz. that in the domain of language and languages interventions will always be necessary if our aim is to ensure some sort of fairness and a reduction of inequality and injustice between the languages involved.

The next question then is: What kind of interventions? Here, London, the world's capital of multilingualism, provides us with a fascinating microcosm, a model really, for trying out good practice and working principles for the use of all kinds of languages in domains such as education, the health sector, the justice system, etcetera. In the United Kingdom (unlike in France), the national language has not been enshrined in the constitution. This pragmatic position has an interesting corollary: language matters, instead of being tied into issues of national prestige, statehood and political symbolism, are linked rather more into societal needs and practical politics and can be tackled from the starting point of general rights for anyone - such as the European Human Rights Legislation (which has been included into the British legal system) as well as the basic right people have - under various charters in fields such as healthcare and the law - to a translation which meets professional standards of communication.

Over the last few decades, this approach has inspired a range of practices of multilingual interaction in London. For example, the well-known slogan 'no taxation without representation', a very basic English principle, has, when necessary, been expanded to include languages other than English: at election time, voters have a right to be informed about the choice of candidates and policies before them, and so large numbers of voters are provided with relevant information in some twenty different languages that are widely used. Other examples are: In the London education sector, one can find private schools offering the full curriculum 
in Welsh, German, Maori, French, Chinese, or Japanese. The well-established freedoms of religion and congregation include the right to worship in the language of one's religious community. The Patient's Charter gives people the right to be properly informed, in a language they can understand, about a medical treatment before they consent to it - so the National Health Service disseminates information on colonoscopy in 13 different languages - Arabic, Bengali, Chinese, Farsi, Greek, Gujarati, Hindi, Polish, Portuguese, Punjabi, Somali, Spanish, Turkish, Vietnamese, and Urdu. A suspect held by the police, or a defendant in a court case, is entitled to the provision of translation and interpretation. And to facilitate all this, language services in some 150 languages are provided by the London Language Line, which offers a humane, social, and often vital service (Salverda 2006: 3).

The result, as we see, is not necessarily a language policy as such, i.e. a policy focussed specifically and exclusively on language. Rather, what we see at work in these London developments are social policies, with an emphasis on matters of contact and communication in civil society. This approach, focussed as it is on people's practical needs in communication, would appear to be both effective and sustainable, and provides us with important building blocks for best practice in how to handle multilingual situations. No less important is that this approach gives room for taking into account the arrival of large numbers of speakers of languages from outside the European Union (EU), which generally have no rights or status at all in Europe - even if they are very present and widely spoken, they are still the big elephant in the room.

In my view, it makes good sense to link up these effective multilingual practices developed in London with the working principles (principles of cooperation, fair distribution, parity of esteem, respect, democracy, and territoriality) Van Parijs has worked out for the reduction of unfairness in the domain of languages.

\section{Van Parijs's Territoriality Principle and the Situation in Fryslân}

My second case concerns the territorial principle proposed by Van Parijs. As he claims in Chapter 5, the territorial principle ('in France one speaks French') is the most important safeguard a language can have: 'language survival requires a territorially differentiated coercive linguistic regime'. This principle is clearly relevant to an understanding of the situation in trilingual Belgium, where it is the first basic principle of the constitution. But while, generally speaking, languages with a territory of their own are doing better than languages without one, there is a problem here. The world today counts some 200 states, as against an estimated 7,000 languages. So, if we were to give each of these languages and 
their communities a concrete, physical, geographical territory of their own, this could only lead to endless conflicts, it would seem - taking us away, precisely, from the justice we are aiming at fostering. Instead, when we want to assign to a language a territory of its own, we should consider how we can do this in such a way that it does contribute to linguistic justice.

The Frisian language situation is a case in point here. Fryslân, the area where Frisian is used, is a wide open space, without natural barriers, not remote, open to the sea and to the continent, and completely integrated into modern Dutch, European, and global society. Within the Netherlands as a whole, the Frisians enjoy a positive image; they are well-respected and seen as a people with character. And they also have a language of their own.

At any rate, that is the case today. Less than a century ago, however, the Frisian language was officially non-existent. In 1864, when Karl Marx visited Amsterdam, he wrote home: 'I've been very well supplied with Dutch literature. But something in Frisian could not be found here, even though there is a bookshop that sells publications in 88 modern languages. The people of Amsterdam evidently feel themselves more connected to the languages of Africa than to the Frisian language - but man always contrives to neglect the things that are nearest to him' (own translation, qtd from Mulder 1997: 125).

Today, the situation of Frisian is rather better than it was in Marx's time. From the 1930s onwards, Frisian has been officially recognized in the fields of education, law, administration, politics, media, religion, and culture. In 2013, this process culminated in a national law on Frisian - the first ever language law in the Netherlands -, backed up by an official agreement between the national and the provincial governments, detailing the provision for Frisian in a wide range of social and cultural domains for the period of 2013-2018.

This is not to say that all is well for Frisian. Within the unified and centralized nation-state that the Netherlands is, Frisian has for a long time been at the receiving end of a tradition of official monolingualism after the French fashion, and today there are still strong pressures on Frisian. There is an ongoing shift away from Frisian towards the national language, Dutch, and one can find negative social attitudes towards Frisian amongst Dutch speaking monolinguals who come and settle in Frisian villages, and not just refuse to learn and speak Frisian but want to impose the sole use of their language, Dutch. In the streets of Leeuwarden - which will be European Capital of Culture in 2018 -, there are no bilingual street signs. Research of its linguistic landscape (cf. Gorter et al. (ed.) 2012) reveals that sixty percent of its street signs are in Dutch, thirty-five percent in English, and the remaining five percent in Frisian reflect the tenuous position of this language (Gorter (ed.) 2012).

This unequal coexistence of the three languages is indicative of the minority position of Frisian. Note that it is often a struggle to get or to retain facilities for Frisian. In education, for example, from 1997 onwards, the innovative approach 
of the Trilingual School has produced good results for children learning Dutch, English, and Frisian in primary school. But the provincial authorities do not have powers over education, and so the further dissemination of this model is dependent on voluntary admission by schools - and only 50 out of 450 primary schools in the province have taken up this model. Similarly, the ongoing Frisian Language Survey shows that the Frisian language is in a stable position, which in the face of the pressures it is exposed to - is quite significant. Intergenerational transmission is the key here, and research shows that Frisian-speaking parents always want more and better Frisian language education for their children - but the schools do not deliver it, pressed as they are by the national government's priorities concerning the three Rs, in Dutch.

In other words, in the trilingual area that is Fryslân, the territorial principle is not a realistic prospect for the Frisian language. The situation we are faced with here is one of a linguistic coexistence within the same territory. This is never a matter of either/or - different languages can easily complement each other; and we can always learn and use each other's languages to cooperate across language barriers. Here lies an opportunity for creative innovation. Instead of an enforceable geographic 'territory', what we need is a more open and creative notion of 'space'. This we can achieve by developing useable spaces of other kinds - in domains that have symbolic value [religious spaces, temples, churches, mosques], cultural significance [works of literature, imagination, mental space], private importance [home, society, club], social meaning [e.g. multilingual education on the formula of Mother Tongue plus Two Other Languages, from the Universal Declaration of Linguistic Rights (Barcelona, 1996)], virtual modernity [e-learning of languages, using private niches (blogs, social media)], or business potential, as in Google Translate, where Frisian is expected to become its $99^{\text {th }}$ or $100^{\text {th }}$ language.

These and other such spaces can be used as havens for communication and for the use, transmission, and enjoyment of languages. Such amended territoriality opens up a space for stimulating new developments - from introducing bilingual street signs to attaining educational excellence by learning more than one language early in life. Such interventions can help to give substance to linguistic coexistence and interaction, making it work for Frisian and sustaining this language in the face of the ongoing dutchification of Fryslân.

\section{The European Charter of Regional Minority Languages}

Our third case is that of the European Charter for Regional or Minority Languages of the Council of Europe, which, with 47 members, is the leading human rights organization on the continent. Although in his book Van Parijs does pay attention to well-known minority languages such as Basque, Catalan, and Gaelic, he does 
not discuss the Charter and the languages it covers. But the case merits our attention. Language issues are an important matter to the Council of Europe. Its Language Policy Unit plays an important role in developing ideas on learning modern languages, on the role of minority and migrant languages in plurilingual education, and on the promotion of language learning.

Of special significance is the Council's Charter for European Regional Minority Languages, which presents a Europe-wide intervention in the domain of languages, focussing on the recognition and support of those languages and their communities, with policy measures aiming at stimulating the preservation, promotion, transmission, and provision of resources for learning, as well as the investment necessary to make this work.

So far, the Charter has been ratified by 24 of its member states. This is a rather recent development: most of the ratifications occurred post-2000, as a precondition for EU membership. At the same time, a number of larger member states - such as France, Greece, Portugal, Russia, and Turkey - have not ratified the Charter despite having significant linguistic minorities within their borders. As things stand today, across Europe, some sixty minority languages - ranging from Albanian, Armenian, and Basque via Frisian, Karelian, Romany, and Saami to Turkish, Welsh, Yezidi, and Yiddish - benefit from official recognition under the Charter. The top scorer here is undoubtedly Romania, with 20 such indigenous minority languages, followed by Herzegovina (16), Poland (15), and Ukraine (13). All in all then, while thanks to the Charter there has been considerable progress over the past twenty years, only a minority of the existing European regional minority languages are covered by the Charter, and we do still have a long way to go.

Despite this patchy situation, the Charter does contribute to the goals defined by Van Parijs in Linguistic Justice - the reduction of inequality, working towards parity of esteem, more respect, fairness, and democracy. The Charter constitutes a mechanism for intervention in the sense of Van Parijs by offering a set of means such as European funding, policies and principles, good practice and monitoring, for the preservation, development, and promotion of minority languages - which all contribute to the achievement of linguistic justice goals such as fairness and equality (c.q. reduction of inequality). The Charter helps to do so in a number of practical ways: first, by providing Information and Documentation: there are more than forty Mercator Regional Dossiers on these minorities available online; secondly, by stimulating networks for learning, aiming at promotion and improvement of language learning in multilingual contact situations, the development of innovative resources, facilities, learning models and strategies for the (re-)vitalization of languages; thirdly, by the exchange and dissemination of best practice, defusion of conflict situations, and moving instead to information and understanding, language learning, and cooperation. 
In 2016, the Charter's agenda will receive a significant boost from this year's European Capital of Culture in Donostia/San Sebastian, where in January the European Language Diversity Summit (ELDS) was launched. Running through the year, the Summit's objectives include: (1) to declare that guaranteeing language diversity and ensuring language development are keys to peaceful coexistence; (2) to create an effective instrument for language equality and revitalizing languages in unfavourable situations; (3) to ensure that language communities are the actors in this process and assert that the civil society's involvement guarantees fair play. In the course of the year, the Summit will develop a protocol for ensuring linguistic equality for each linguistic community that will be presented at a twoday conference in December 2016 in Donostia/San Sebastian. The ELDS project is sponsored by a European coalition of, among others, the Basque Language Organization, the European Centre for Minority Issues in Flensburg, the European Language Equality Network (ELEN), the Unrepresented Nations and Peoples Organization (UNPO), the Linguapax organization, as well as the writers' organization PEN International, with its Girona Manifesto of 2011 demanding that 'the right to use and protect one's own language must be recognized by the United Nations as one of the fundamental human rights'.

There can be no doubt that this process of fully implementing the European Charter for Regional Minority Languages in all the member states of the Council of Europe will be a long, hard slog. The Charter is not EU Law but a voluntary, optional extra for individual governments; it is not in force across all of the EU and not included amongst the basic rights that a European citizen could call into effect; and EU Law takes no account of group or community rights in the domain of culture or language. Difficult as it may be, then, when it comes to realizing linguistic rights and justice for endangered languages, we must see the Charter and what it can offer as a very basic and very necessary first step which does contribute to the goals defined by Van Parijs in his Linguistic Justice - viz. reduction of inequality, working towards parity of esteem, more respect, fairness, and democracy.

\section{Outlook}

Our findings above suggest that bringing these various strands of thinking and practice together will be to the benefit of the endangered languages of Europe and the world. There is a clear urgency to this since, as a matter of fact, for large parts of the world's population, we are still a very long way off a real implementation of language rights.

UNESCO - like other international bodies we have mentioned - is working hard in this direction, with its IFAP (Information for All Programme), its Recommendation for Universal Access to Multilingual Cyberspace, and its 
Atlas of Endangered Languages, which already includes more than 2,500 such languages. But why stop there? A comprehensive, state-of-the-art Atlas of the World's Languages - giving data on the users, the structure and the vitality of all those languages, and using the latest technology - does not even exist and is a much-needed basic resource.

It is technically feasible. It will contribute to linguistic justice for all. It is a basic necessity to expand and complete our knowledge of the world's linguistic diversity. So, what is keeping us back?

\section{References}

ARGENTER, Joan A.-Brown, R. McKenna (eds). 2004. Endangered Languages and Linguistic Rights: On the Margins of Nations. Proceedings, $8^{\text {th }}$ FEL Conference, Barcelona.

CALVET, Louis-Jean. 2011. Il était une fois 7000 langues. Paris.

EXTRA, Guus-GORTER, Durk (eds). 2001. The Other Languages of Europe. Clevedon.

FISHMAN, Joshua A. 1991. Reversing Language Shift. Clevedon.

Gorter, Durk et al. (eds). 2012. Minority Languages in the Linguistic Landscape. London.

MCCONAGLE, Tarach. 2013. Freedom of Expression of Minorities in the Digital Age: Staking Out a New Research Agenda. JEMIE Journal of Ethnopolitics and Minority Issues 12(4): 1-15.

MOSELEY, Christopher. 2007. Encyclopedia of the World's Endangered Languages. London.

MULDER, Bertus. 1997. Fryske Taalpolityk. Boalsert.

OSTLER, Nick. 2010. The Last Lingua Franca. English until the Return of Babel. London.

SALVERDA, Reinier. 1998. Frisian. In: Glanville Price (ed.), Encyclopedia of the Languages of Europe, 177-184.

Salverda, Reinier. 2006. Multilingual London and Its Literatures. In: Opticon 2006/1: 1-15. www.ucl.ac.uk/opticon1826/archive/issue1/ VfPMultilingualLondonPDF.pdf.

SPOLSKY, Bernard. 2009. Language Management. Cambridge.

VAN PARIJS, Philippe. 2011. Linguistic Justice for Europe and for the World. Oxford. 


\section{Websites}

CIPL - Comité International Permanent de Linguistes (CIPL) - www.ciplnet.com

CofE Charter - Council of Europe, European Charter for Regional Minority Languages. At: http://conventions.coe.int/treaty/en/Treaties/Html/148.htm ELDS - European Language Diversity Summit - www.linguapax.org/english/ what-we-do/donostia-european-language-diversity-summit

FEL - Foundation for Endangered Languages (FEL) - www.ogmios.org

Mercator European Research Centre on Multilingualism and Language Learning - www.mercator-research.eu

PEN International Writers Organization - www.pen-international.org TLA - The Language Archive (TLA) - https://tla.mpi.nl

UNESCO Atlas of the World's Languages in Danger - www.unesco.org WWF: Biocultural Diversity: Threatened Species, Endangered Languages - www. wwf.panda.org 